\title{
Leitura de Artigos Científicos: uma Estratégia para o Ensino Remoto de Metodologia da Pesquisa
}

\author{
Lafayette B. Melo ${ }^{1}$ \\ ${ }^{1}$ Unidade Acadêmica de Informática - Instituto Federal da Paraíba (IFPB) \\ CEP 58015-435 - João Pessoa - PB - Brazil \\ lafayette.melo@ifpb.edu.br
}

\begin{abstract}
This work used a strategy of applying the content of reading scientific articles in two academic periods during the pandemic to investigate how classes were developed remotely and why certain results were positive or not. It was intended to overcome the lack of reports that present studies on specific contents of scientific methodology disciplines, taught in the Flipped Classroom methodology, more especially in computer technology courses, in a remote format and qualitatively structured as a case study. One of the conclusions is that the result was positive, as the students identified and understood what should be included in the scientific articles they read.
\end{abstract}

Resumo. Este trabalho utilizou uma estratégia de aplicação do conteúdo de leitura de artigos científicos em dois periodos letivos durante a pandemia para investigar como as aulas foram desenvolvidas remotamente e o porquê de certos resultados serem ou não positivos. Pretendeu-se suprir a falta de relatos que apresentem estudos sobre conteúdos especificos de disciplinas de metodologia científica, lecionados na metodologia de Sala de Aula Invertida, mais especialmente em cursos tecnológicos de informática, em um formato remoto e estruturado qualitativamente como estudo de caso. Uma das conclusões é que o resultado foi positivo, já que os alunos identificaram e compreenderam o que deveria ter nos artigos científicos lidos.

\section{Introdução}

O ensino de disciplinas de metodologia da pesquisa científica em cursos superiores tem peculiaridades e alcances próprios. Nessas disciplinas se aprende desde os fundamentos do pensamento científico, passando por discussões sobre o método científico e o uso da redação científica até a definição de um problema científico e técnicas de coleta de dados. Na nossa instituição, essas disciplinas são desenvolvidas em cursos tecnológicos, licenciaturas e bacharelados e na área de informática temos Métodos e Técnicas de Pesquisa (MTP) para o curso de Redes de Computadores (RD) e Sistemas para Internet (SI). Este trabalho utilizou estratégias de aplicação do conteúdo de leitura de artigos científicos em dois períodos (2020.1 e 2020.2) para investigar como as aulas foram desenvolvidas remotamente e o porquê de certos resultados serem ou não positivos.

A aula sobre leitura de artigos científicos foi feita sincronamente e on-line, direcionada à prática de leitura dos alunos, acompanhada ao mesmo tempo por orientações do professor, que interagia via uma reunião do Google Meet, criada via Google Classroom. O professor verificava o processo de leitura na medida que os alunos iam preenchendo uma planilha compartilhada por todos em que havia colunas 
nas quais se informava o que havia sido compreendido do problema, do objetivo, dos resultados, das discussões e da metodologia empregada no artigo. Para que tal procedimento já fosse feito no início da aula, em uma aula anterior o professor orientava que os alunos estudassem o assunto, conforme alguns pressupostos do que é chamado de Sala de Aula Invertida, de acordo com Bergmann e Sams (2012) e Valente (2018).

Em trabalho recente, Vieira e Seco (2020) cita pesquisa que mostra que a Sala de Aula Invertida pode ser uma ferramenta viável para potencializar e dar continuidade na rotina de estudos, mas não detalha quais seriam os procedimentos para empregá-la remotamente em tempos de pandemia. Em outro trabalho atual, Leite (2021) elenca metodologias e tecnologias que podem ser usadas pelos professores e quais seriam viáveis em um levantamento feito com professores, descobre-se que a Sala de Aula Invertida é conhecida por $48 \%$ dos professores, mas não se descreve como ela poderia ser utilizada seja remotamente ou outra forma qualquer a distância. Esta pesquisa pretende suprir a falta de relatos com estudos sobre conteúdos específicos de disciplinas de metodologia científica, mais especialmente em cursos tecnológicos de informática, em um formato remoto ocasionado pela pandemia da Covid-19 e estruturado qualitativamente como estudo de caso.

\section{Métodos}

A pesquisa foi feita em caráter exploratório por meio de um estudo de caso, de acordo com recomendações de Yin (2015), e observações sobre uso do método qualitativo conforme Creswell (2010) e Yin (2016). O trabalho pode ser caracterizado como um estudo de caso, pois é uma investigação empírica ao longo do tempo para responder perguntas que tratem mais do "como" e do "por que" do fenômeno investigado. Além disso, o contexto de estudo é real e verticalizado, com o pesquisador imerso na pesquisa com o papel de professor das disciplinas de metodologia de pesquisa. Outro fator para considerar a pesquisa um estudo de caso é a sua contemporaneidade e o fato de o fenômeno e o contexto não estarem claramente evidentes: a leitura dos artigos científicos é realizada pelos alunos de modo remoto, em um ambiente virtual de aprendizagem - o Google Classroom - com interação feita por ferramenta de Webconferência - o Google Meet - e uso do Google Planilhas em cada sessão de aula criada via Classroom. Para acompanhar o registro on-line da leitura dos alunos demanda-se considerar diferentes fatores para compreensão do processo. Isso, sem contar que se procurou seguir parte das diretrizes de uma sala de aula invertida de acordo com Silveira (2018), indicando aos alunos um material previamente à aula, para estudarem o que seria a leitura superficial e profunda de artigos científicos Para assegurar uma análise o mais próximo possível das questões iniciais de pesquisa, foi definida a unidade de análise como o processo de leitura dos alunos registrado on-line em um planilha compartilhada para todos os alunos de cada turma, ou seja, foi feito o design de múltiplos casos com uma unidade de análise, conforme mostrado na Figura 1.

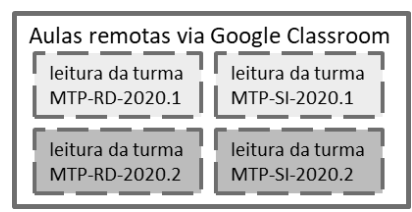

Figura 1. Contexto das aulas remotas e unidade de análise de leitura

Foi definido um protocolo de estudo de caso, cujo resumo é mostrado adiante.

1 - Visão geral - registro das questões de pesquisa para delineamento da investigação. 
2 - Preparação das aulas para o estudo de caso - foi orientado aos alunos, conforme pressupostos de uma aula invertida, que lessem previamente à aula um material construído em um mural produzido no Padlet $^{1}$, mostrado na Figura 2. Também foi preparado um tópico no Google Classroom com a estruturação da aula remota síncrona em que há uma atividade que é o preenchimento de informações nas colunas de uma planilha, na respectiva linha de cada aluno. Tais informações dizem respeito ao que cada aluno compreendeu no artigo (objetivo, problema, análise etc.), tanto em uma leitura superficial quanto em uma leitura profunda. A Figura 3 mostra parte do tópico com a chamada para o exercício e um zoom da planilha compartilhada com a turma.

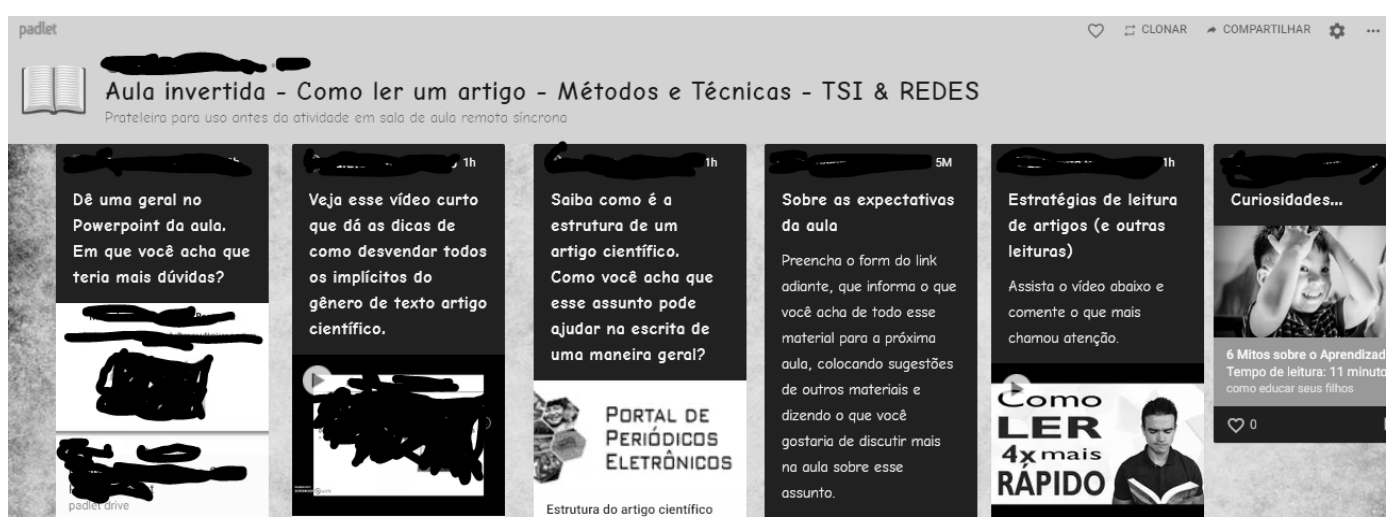

Figura 2. Conteúdo para estudo antes do exercício de leitura em aula

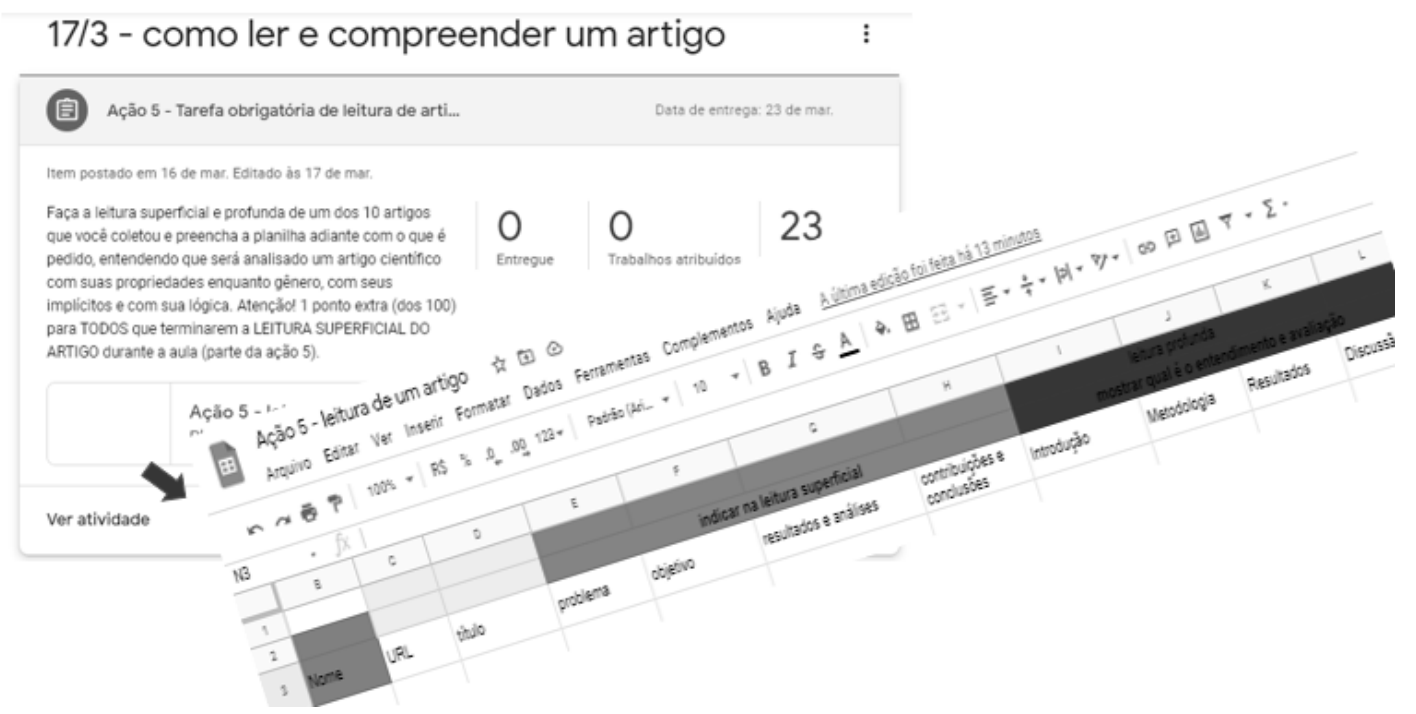

Figura 3. Atividade de leitura do artigo e planilha preenchida durante a leitura

3 - Procedimento de coleta de dados - para triangulação dos dados foram gravados formatos diferenciados: vídeo gravado no Meet, conversações no chat do Meet, comentários que os alunos fizeram sobre o conteúdo da aula invertida no Mural do Classroom ou no Meet e um miniquestionário de satisfação dos alunos. Depois de verificados os dados registrados, para melhor relacionamento dos objetivos da pesquisa com o contexto e unidade de análise, foi definido que se restringiriam para codificação

\footnotetext{
${ }^{1}$ https://padlet.com/
} 
os quatro arquivos correspondentes às planilhas, para serem manipulados no ATLAS.ti ${ }^{2}$. Trechos dos arquivos foram codificados a priori com: título (do artigo), objetivoidentificado, objetivo-nãoidentificado, problema-identificado, problemanãoidentificado, metodologia-identificada, metodologia-nãoidentificada, resultadosidentificados e resultados-nãoidentificados, conforme a Figura 4.

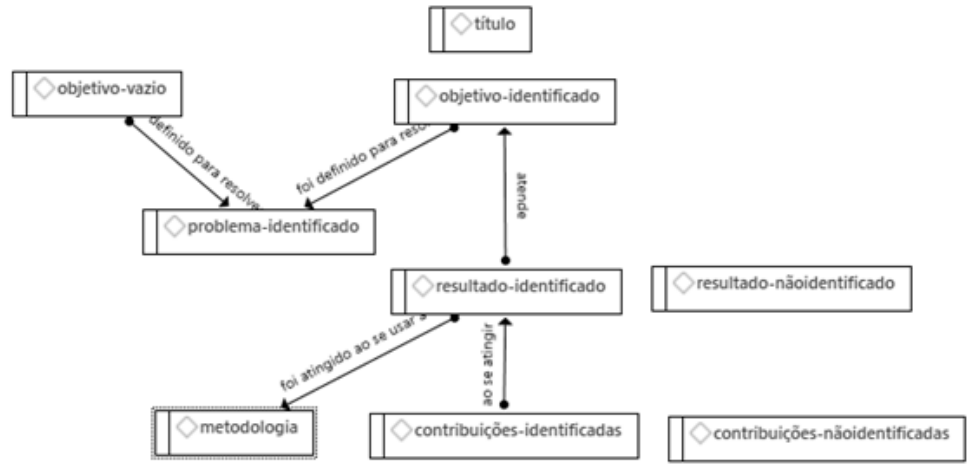

Figura 4. Codificação das planilhas de leitura

\section{Resultados e Discussão}

Cada aluno escolhia o artigo a ser lido dentre os que foram buscados em repositórios em uma atividade anterior. Durante as aulas, foi acordado que o exercício referente ao conteúdo de "como ler um artigo" iniciaria na própria aula, mas, se o aluno não finalizasse, teria mais uma semana para terminar. Observou-se na planilha que nem todos preencheram informações referentes à leitura profunda, mas todos, nas quatro turmas, preencheram ao menos as informações sobre leitura superficial. Ao ser gerada a nuvem de palavras com os títulos codificados de todas as turmas, tem-se a Figura 5.

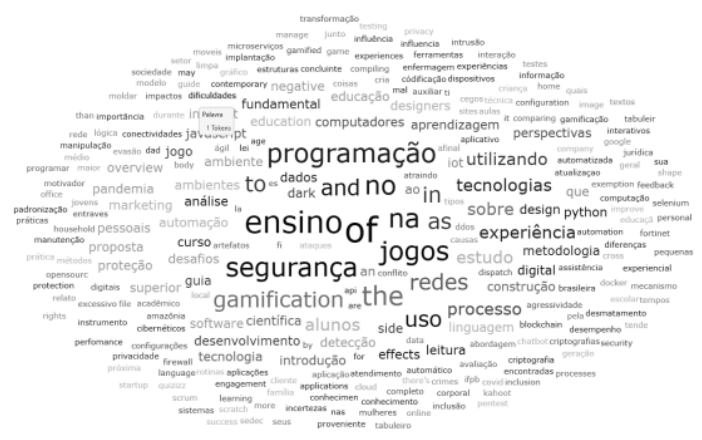

Figura 5. Palavras dos títulos dos artigos

Observa-se uma tendência geral nos títulos por temas que se referem a segurança, ensino, jogos, programação, gamificação, mas, em um segundo nível, análise, dados, aprendizagem e pandemia. Em nuvens geradas em separado para as quatro turmas, há a ocorrência de pandemia, o que implica que nos dois períodos pandêmicos houve interesse pela temática (especialmente seus efeitos na vida profissional e acadêmica). $\mathrm{O}$ tema segurança ocorreu semelhantemente tanto em RD quanto SI, embora se esperasse que fosse um tema mais de RD. Na geração de uma tabela código-documento foi verificado que em todas as 4 turmas havia sempre uma

\footnotetext{
${ }^{2}$ https://atlasti.com/
} 
frequência bem maior de objetivo-identificado, problema-identificado, metodologiaidentificada e resultados-identificados do que seus correspondentes não identificados. Nas colunas de leitura profunda havia poucos posicionamentos sobre as seções dos artigos - isso pode ocorrer pelo fato de os alunos não terem experiência com métodos de pesquisa específicos, o que tornaria insegura alguma crítica ou posicionamento.

Sobre as relações entre os códigos "identificado" e "não-identificado", verificouse sempre uma regularidade de 10 a $20 \%$ dos "não-identificados" (preenchidos erradamente ou deixados em branco na planilha), o que significa que houve uma frequência maior de compreensão do que incompreensão do que deve ter em um artigo científico. O percentual é feito em cima não dos alunos matriculados na disciplina, mas dos que participaram das atividades. Na pandemia houve uma evasão em torno de metade dos alunos em cada turma. Exemplificando, a turma de MTP-RD-2020.1 tinha quarenta alunos matriculados, mas 22 progrediram no ensino remoto. Destes, três foram codificados com objetivo-nãoidentificado para a leitura do artigo, o que dá um percentual de $13 \%$ de erros na turma. Em relação ao questionário aplicado com os alunos, temos os resultados na Tabela 1. Foi ainda feita uma pergunta subjetiva sobre quais outros recursos tecnológicos deveriam ser colocados na aula, mas ou a resposta era "nada" ou "nenhum" ou simplesmente a pergunta não foi respondida.

Tabela 1. Miniquestionário sobre aula de como ler um artigo

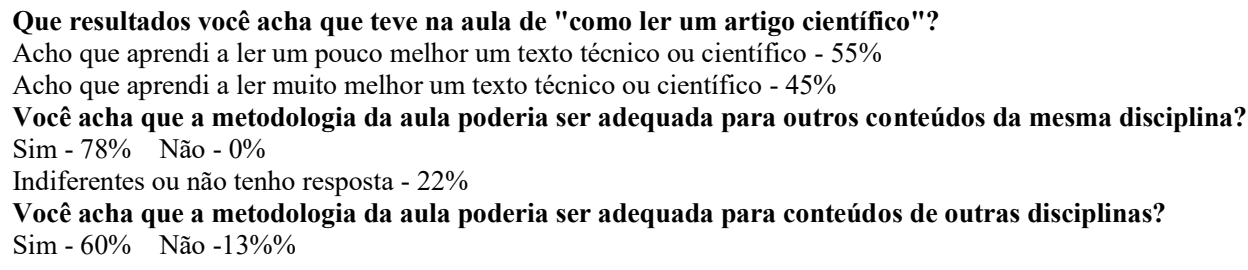

Depreende-se que os alunos que responderam viram a experiência de forma positiva, já que responderam apenas que aprenderam muito ou um pouco melhor a ler um artigo técnico ou científico. Sobre adequar este tipo de aula, houve um percentual maior de alunos que gostariam de adequar a aula a conteúdos da mesma disciplina $(78 \%)$ do que a outras disciplinas $(60 \%)$. Tal fato pode estar relacionado com o direcionamento das atividades: sempre há só leituras de artigos científicos. Foi satisfatório o entendimento de como os alunos compreendem um artigo e identificam corretamente seus elementos, mas o motivo de a leitura profunda não alcançar o mesmo resultado da leitura superficial está mais relacionado com a maturidade em pesquisa, já que havia uma semana adicional para quem não fizesse a tarefa durante a aula.

\section{Conclusões}

O trabalho demonstrou como pode ser feita a atividade de leitura de artigos científicos em disciplinas de metodologia científica e correlacionou os "por quê"s de se obter determinados resultados em uma experiência concreta mediada pelo computador em plena pandemia da Covid-19. Apesar de se avaliar o resultado como positivo, as escolhas dos temas foram influenciadas pelo momento histórico, o que demanda que nas próximas experiências se relacione temas de pesquisa com o momento. Pretende-se relacionar o conteúdo de aula com outros textos técnicos, além dos científicos e novas pesquisas estão sendo estudadas para adicionar elementos de gamificação ao método empregado bem como aplicá-lo no conteúdo de escrita de um artigo científico. 


\section{Referências}

Bergmann, J. and Sams, A. (2012) "Sala de aula invert!da: uma metodologia ativa de aprendizagem", LTC, Rio de Janeiro, Brazil.

Creswell, J. H. (2010) "Projeto de pesquisa: métodos qualitativo, quantitativo e misto", Sage, Porto Alegre, Brazil.

Leite, B. S. (2021) Tecnologias Digitais e Metodologias Ativas: Quais são conhecidas pelos professores e quais são possíveis na educação? In Revista Eletrônica VYDIA, v. 41, n. 1, p. 185-202.

Silveira, S. R., Pereira, A. S., Bertolini, C., Parreira, F. \& Bigolin, N. (2018) Educação a Distância, Sala de Aula Invertida e Aprendizagem Baseada em Problemas: possibilidades para o ensino de programação de computadores In Congresso Brasileiro de Informática em Educação.

Valente, J. A. (2018) "A sala de aula invertida e a possibilidade do ensino personalizado" In Metodologias Ativas para uma Educação Inovadora: uma abordagem teórico-prática, Penso, Porto Alegre, Brazil.

Vieira, M. F. \& Seco, C. (2020). Education in the context of the COVID-19 pandemic: a systematic literature review (A Educação no contexto da pandemia de COVID-19: uma revisão sistemática de literatura). In Brazilian Journal of Computers in Education (Revista Brasileira de Informática na Educação - RBIE), 28, p. 10131031. DOI: 10.5753/RBIE.2020.28.0.1013

Yin, R. K. (2015) "Estudo de caso: planejamento e métodos", Bookman, Porto Alegre Brazil.

Yin, R. K. (2016) “Pesquisa qualitativa do início ao fim”, Penso, Porto Alegre - Brazil. 